\title{
Predicting of oak wood properties using X-ray inspection: representation, homogenisation and localisation. Part II: Computation of macroscopic properties and microscopic stress fields
}

\author{
Patrick Perré and Éric Badel \\ Laboratoire d'Étude et de Recherche sur le Matériau Bois, UMR 1093 INRA/ENGREF/Université Henri Poincaré Nancy I, ENGREF, \\ 14, rue Girardet, 54042 Nancy Cedex, France
}

(Received 8 January 2002; accepted 21 May 2002)

\begin{abstract}
This paper is the second part of a comprehensive approach that allows the elastic and shrinkage properties of oak to be determined from the properties of the anatomical tissues and the spatial distribution of those tissues, obtained by a high resolution digital X-ray imaging device. The computation of the macroscopic properties employs a 2-D numerical tool, called MorphoPore, that utilises periodic homogenisation over the representative volume. The paper starts with the derivation of the mechanical formulation and analyses the effect of mesh refinement on the overall solution quality. Thereafter, a first example is presented that depicts the effect of fibre proportion and fibre zone shape on the macroscopic properties using a virtual anatomical pattern and a second example uses finite element meshes built from actual patterns coming from two positions of the same tree, just before and just after thinning the forest stand. The approach presented in this research allows the increase of rigidity and shrinkage coefficients due to the increase of the annual ring width to be quantified. Finally, two localisation problems are proposed in which the micro-stress fields are computed from the macroscopic loading. The first case assumes that no macroscopic stress field exists (free shrinkage configuration), whereas the second assumes that the macroscopic displacement is constrained along one direction (drying configuration).
\end{abstract}

wood / homogenisation / modelling / numerical computation

Résumé - Utilisation de l'imagerie $X$ pour la prédiction du bois de chêne : représentation, homogénéisation et localisation. Partie II : Calcul des propriétés macroscopiques et des champs de micro-contraintes. Cet article est la deuxième partie d'une approche complète qui permet de prédire les propriétés élastiques et de retrait du chêne à partir des propriétés des tissus qui le composent et de leur distribution spatiale décrite par un système d'imagerie $\mathrm{X}$ de haute résolution spatiale. Le calcul des propriétés macroscopique est effectué par homogénéisation de milieux périodiques sur un volume élémentaire représentatif à partir d'un code numérique 2-D, appelé MorphoPore. Ce papier commence par la présentation de la formulation mécanique. Viennent ensuite quelques considérations sur l'effet du raffinement du maillage numérique. Â l'aide de plans ligneux virtuels, le premier exemple d'application montre l'effet de la proportion des fibres et de la forme de zone de fibres sur les propriétés macroscopiques. Le deuxième exemple utilise deux plans ligneux réels, provenant du même arbre. La seconde zone produite juste après éclaircie, a un accroissement annuel très important. Notre approche permet de quantifier l'augmentation des rigidités et des coefficients de retrait. Enfin, deux exemples de localisation sont proposés. Cette démarche permet le calcul des champs de micro-contraintes à partir du chargement macroscopique de la structure. Le premier cas considère l'absence de contrainte macroscopique (retrait libre) tandis que le deuxième considère que le déplacement est bloqué selon une direction (zone externe d'une planche durant le séchage).

bois / homogénéisation / modélisation / calcul numérique

\section{INTRODUCTION}

Wood is a composite material that possesses numerous interesting properties: low density, high longitudinal strength, high impact strength, low thermal conductivity, low thermal effusivity, low energy input, aesthetic quality, etc. However, in spite of these qualities, the development of wood as a building material is constrained for two major reasons: wood is highly variable and most wood species have a low natural durability. This two-part paper proposes a new approach that could enable the timber industry, in the near future, to take a better advantage of wood variability.

The explanation of wood properties and its variability from the anatomical structure is already well documented in the literature. Some well-known works or reviews, including those

* Correspondence and reprints

Tel.: 03833968 90; fax: 03833968 47; e-mail: perre@engref.fr 
of Barkas, Boutelje and Kelsey for example, are several decades old $[6,8,19]$. These works present careful observations, measurements and statistical analysis and remain absolutely necessary in wood science before any modelling can take place $[3,4,7,11,22,23]$. Most modelling works consider wood at the cellular level, using the beam theory to formulate the structural behaviour. Although both analytical [12, 13, 20, 32] and numerical solutions [2, 10, 16, 27] have been proposed, only the latter are able to model the actual cellular arrangement of wood.

In spite of these numerous works, the prediction of macroscopic properties of heterogeneous species, such as ring porous hardwoods, using a deterministic approach is still rare. To our knowledge, only some explanations and analytical models are available to explain the effect of ray cells on transverse anisotropy ratio [8, 14, 18, 19].

This work is devoted to the prediction of oak properties from the tissue arrangement at the growth ring level. A numerical approach is proposed, which uses a finite element method to solve the homogenisation problems applied to periodic structures $[10,27]$. This deterministic approach requires two kinds of local information:

1 - Characterisation of the microscopic components: the intrinsic properties of each component of the composite material have to be known.

2 - A geometrical (virtual) description of the material structure must be made.

The characterisation of each tissue requires the use of very specific experimental devices and intricate measurements on micro-samples. This step was the primary objective of already published works [3, 4]. The description of the oak annual ring was the aim of the first part of this paper [5]. The work presented in Part I also explains the whole procedure that allows the anatomical pattern of an actual wood sample to be meshed using finite elements. This work involved several key steps: sample cutting, X-ray imaging, image enhancement, image segmentation, length controlled discretisation of the contours and mesh generation.

The present part (Part II) is devoted to the computation of macroscopic properties and microscopic stress fields (figure 1). It comprises three steps:

- Homogenisation: Homogenisation computations are performed using a periodic formulation. Four elementary problems are solved: three for the elastic behaviours in the transverse plane and one for shrinkage. The numerical solutions are computed with a finite element tool, called MorphoPore, specifically developed for that purpose [25, 26]. Some considerations on the effect of mesh refinement are discussed also.

- Computation examples: The first example depicts the effect of fibre proportion and fibre zone shape on the macroscopic properties. The second example uses the anatomical morphology coming from two positions of the same tree and allows the effect of growth rate on macroscopic properties to be quantified.

- Localisation: Localisation is one of the interesting possibilities of the mechanical formulation. It consists in calculating the microscopic stress field that results from any macroscopic configuration. The solutions of the elementary homogenisation problems are used to calculate these

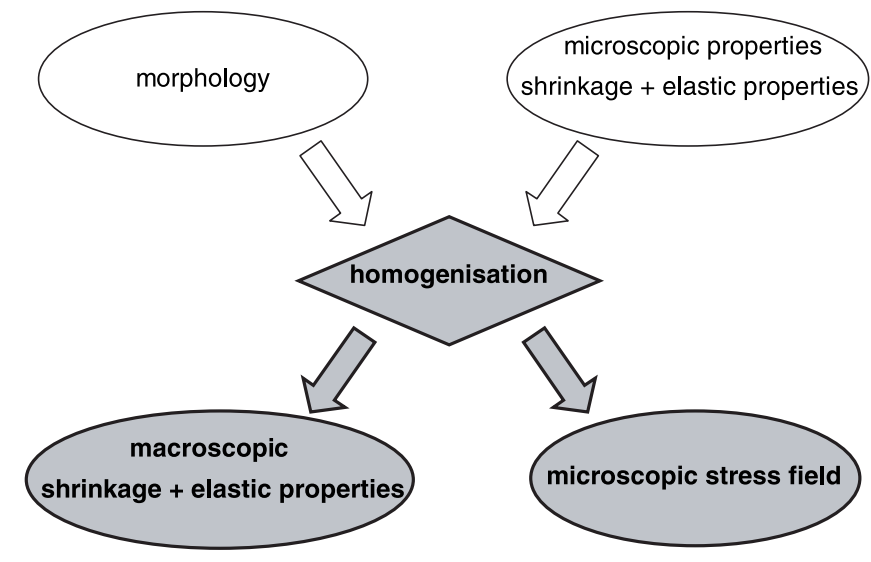

Figure 1. Principle of homogenisation: Part II of this paper is devoted to the calculation of the macroscopic properties and the determination of the microscopic stress fields that result from the macroscopic configuration.

microscopic stress fields. Two localisation problems are proposed: the first case assumes that no macroscopic stress field exists (free shrinkage configuration), whereas the second assumes that the macroscopic displacement is constrained along one direction (drying configuration).

\section{HOMOGENISATION}

Homogenisation is one of the formulations that allows the prediction of the macroscopic properties from the microscopic description of a heterogeneous medium [1, 16, 27-29].

In the case of a medium assumed to be periodic, for which the micro and macro scales do not interfere, homogenisation reduces to that of solving a steady-state physical problem over the unit cell. Specific periodic boundary conditions are associated with this problem.

The principle of the formulation uses a double scale coordinate system. The macroscopic position is defined by vector $\boldsymbol{x}\left(\mathrm{x}_{1}, \mathrm{x}_{2}, \mathrm{x}_{3}\right)$ while the position within the Representative Elementary Volume (REV) is defined by vector $\boldsymbol{y}\left(\mathrm{y}_{1}, \mathrm{y}_{2}, \mathrm{y}_{3}\right)$. Variables $\boldsymbol{x}$ and $\boldsymbol{y}$ are supposed to be independent. This description allows the variations in space to be divided into:

- the part resulting from the large distance change for a point situated at the same position of the unit cell (points $M$ and M' in figure 2, for instance, with different values of $\boldsymbol{x}$ );

- the part resulting to the short distance effect that results from points situated at the same macroscopic position $\boldsymbol{x}$, but at different locations of the unit-cell (for instance, points $M$ and M' in figure 2 with different values of $\boldsymbol{y}$ ).

A small parameter $\varepsilon$ is defined, which denotes the ratio that exists between the macroscopic and the microscopic scales (figure 2). One classical way to obtain the final problems to be solved is to proceed to a formal expansion of the physical formulation with respect to the successive power of the small parameter [21, 28, 29].

According to this double co-ordinate system, the aim of homogenisation is to derive the local problem in order to be 


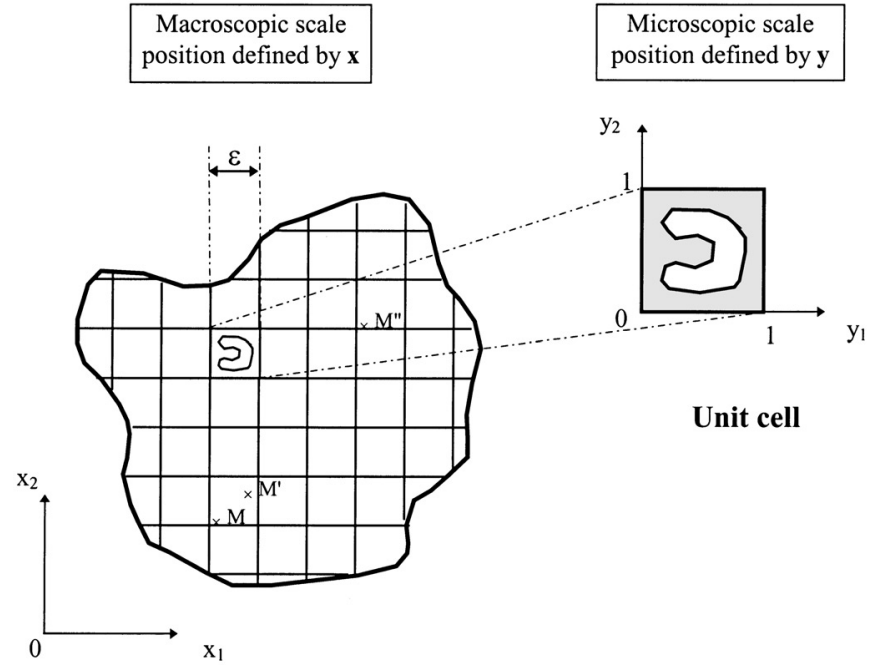

Figure 2. Principle of formal expansion used to derive the hydroelastic formulation.

able to predict the macroscopic properties. The initial problem starts with a classical mechanical equilibrium formulation that accounts for local shrinkage. We assume that no volume forces act. At the level of one unit cell, specific periodic conditions appear instead of the classical boundary conditions (traction force and/or displacement conditions):

$$
\left\{\begin{array}{l}
\sigma_{\mathrm{ij}, \mathrm{j}}=0 \\
\sigma_{\mathrm{ij}}=a_{\mathrm{ijkl}}\left\{e_{\mathrm{kl}}(u)-s_{\mathrm{kl}} H\right\} \\
\bar{\sigma} \cdot \bar{n}=\text { anti-periodic } \\
e(u) \text { periodic. }
\end{array}\right.
$$

In (1), $\sigma$ is the stress tensor, $a$ the elastic constitutive equation, $e$ the strain tensor resulting from the displacement field $u$, $s$ the strain tensor due to shrinkage and $n$ the external unit vector at the boundary. $H$ is the macroscopic field responsible for shrinkage and because shrinkage appears in wood only within the hygroscopic range, $H$ is calculated from the moisture content $X\left(\mathrm{~kg}^{-1}\right.$, dry basis) using the following formula:

$$
H=\min \left(X, X_{\mathrm{fsp}}\right)-X_{\mathrm{fsp}}
$$

where $X_{\mathrm{fsp}}$ is the moisture content at the fibre saturation point. Within the domain of free water, $H$ is equal to zero, within the domain of bound water, $H$ has a negative value.

The displacement field $u$ is written as an asymptotic expansion in successive power of $\varepsilon$ :

$$
u_{i}(\boldsymbol{x}, \boldsymbol{y})=u_{i}^{(0)}(\boldsymbol{x}, \boldsymbol{y})+\varepsilon u_{i}^{(1)}(\boldsymbol{x}, \boldsymbol{y})+\varepsilon^{2} u_{i}^{(2)}(\boldsymbol{x}, \boldsymbol{y})+\ldots
$$

According to the double coordinate system, we can derive the following rule for the spatial derivative:

$$
\nabla \psi=\frac{1}{\varepsilon} \frac{\partial \psi}{\partial \boldsymbol{y}}+\frac{\partial \psi}{\partial \boldsymbol{x}} .
$$

Applying this rule to equation (1b) leads to an asymptotic expansion of the stress tensor:

$$
\begin{gathered}
\sigma_{\mathrm{ij}}=\varepsilon^{-1} \sigma_{\mathrm{ij}}^{-1}+\sigma_{\mathrm{ij}}^{(0)}+\varepsilon \sigma_{\mathrm{ij}}^{(1)}+\varepsilon^{2} \sigma_{\mathrm{ij}}^{(2)}+\ldots \\
\sigma_{\mathrm{ij}}^{(-1)}=a_{\mathrm{ijk} \mathrm{l}}\left\{e_{\mathrm{ykl}}\left(u^{(0)}\right)\right\} \\
\sigma_{\mathrm{ij}}^{(0)}=a_{\mathrm{ijkl}}\left\{e_{\mathrm{ykl}}\left(u^{(1)}\right)+e_{\mathrm{xkl}}\left(u^{(0)}\right)-s_{\mathrm{kl} l} H\right\} \\
\sigma_{\mathrm{ij}}^{(1)}=a_{\mathrm{ijkl}}\left\{e_{\mathrm{ykl}}\left(u^{(2)}\right)+e_{\mathrm{xkl}}\left(u^{(1)}\right)\right\} \\
\sigma_{\mathrm{ij}}^{(2)}=\ldots
\end{gathered}
$$

The same rule for the space derivative applies for the divergence of the stress tensor, hence:

$$
\sigma_{\mathrm{ij}, \mathrm{j}}=\frac{\partial}{\partial x_{j}}\left(\sigma_{\mathrm{ij}}\right)+\frac{1}{\varepsilon} \frac{\partial}{\partial y_{j}}\left(\sigma_{\mathrm{ij}}\right) .
$$

Let us now separate the spatial scale by letting $\varepsilon$ tend towards 0 . In taking this limit lies the fact that we first assumed the two scales to be independent. The only possibility for the balance equation to remain valid is to cancel each power of $\varepsilon$. Order -2 gives:

$$
\frac{\partial}{\partial y_{j}}\left\{a_{\mathrm{ijkl}}\left(e_{\mathrm{ykl}}\left(u^{(0)}\right)\right)\right\}=0 \text { with } u^{(0)} \mathrm{Y} \text {-periodic }
$$

a being coercitive, equation (8) implies that $u^{(0)}$ is a function of $\boldsymbol{x}$ only.

Going further at order -1 gives:

$$
\frac{\partial}{\partial y_{j}}\left\{a_{\mathrm{ijkl}}\left[\left(e_{\mathrm{ykl}}\left(u^{(1)}\right)\right)+\left(e_{\mathrm{xkl}}\left(u^{0}\right)\right)-s_{\mathrm{kl}} H\right]\right\}+a_{\mathrm{ijkl}} \frac{\partial}{\partial x_{j}}\left(e_{\mathrm{xkl}}\left(u^{0}\right)\right)=0
$$

because $u^{(0)}$ is only a function of $\boldsymbol{x}$, the last term in the left hand side vanishes.

Finally, the order 0 is required to close the problem. Keeping in mind that $\sigma_{\mathrm{ij}}^{(1)}$ is anti-periodic and integrating the resulting equation over the unit cell, we finally obtain:

$$
\frac{\partial}{\partial x_{i}}\left\langle\sigma_{\mathrm{ij}}^{(0)}\right\rangle=0
$$

This equation represents the macroscopic behaviour of the material. Now, in order to get the macroscopic properties, we return to equation (9). Because of the linear constitutive equation, $u^{(1)}$ depends linearly on $u^{(0)}$ and $H$. So, we seek a solution of the following form:

$$
u^{(1)}=\xi^{\operatorname{lm}} e_{\mathrm{xlm}}\left(u^{(0)}\right)+w H^{(0)}
$$

Due to the linearity of the formulation, the elementary solutions $\xi^{\operatorname{lm}}$ and $w$ do not depend on the macroscopic variable $\boldsymbol{x}$. Each has to be calculated only once by solving the problem 
corresponding to the dimensionless macroscopic fields. More precisely:

$$
e_{\mathrm{xij}}\left(u^{(0)}\right)=\Pi_{\mathrm{ij}}^{\ell \mathrm{m}}=\frac{1}{2}\left(\delta_{\mathrm{i} \ell} \delta_{\mathrm{jm}}+\delta_{\mathrm{jm}} \delta_{\mathrm{i} \ell}\right) \text { and } H^{(0)}=0
$$

for problem $\mathrm{m}$ associated to $\xi^{\mathrm{lm}}$,

$e_{\mathrm{xij}}\left(u^{(0)}\right)=0$ and $H^{(0)}=1$ for the problem associated to $w$.

Finally, the following problems are required to be solved over the unit cell:

$$
\begin{gathered}
\frac{\partial}{\partial y_{j}}\left[a_{\mathrm{ijk} \ell} e_{\mathrm{k} \ell}\left(\xi^{\mathrm{pq}}\right)\right]=-\frac{\partial}{\partial y_{j}}\left[a_{\mathrm{ijk} \ell} e_{\mathrm{k} \ell}\left(\Pi_{\mathrm{pq}}^{\mathrm{k} \ell}\right)\right] \\
\frac{\partial}{\partial y_{j}}\left[a_{\mathrm{ijk} \ell} e_{\mathrm{k} \ell}(w)\right]=+\frac{\partial}{\partial y_{j}}\left[a_{\mathrm{ijk} \ell} s_{\mathrm{k} \ell}\right] .
\end{gathered}
$$

The knowledge of each basic solution allows the macroscopic properties to be calculated. The simplest and wellknown formula concerns the elastic properties:

$$
A_{\mathrm{ijkh}}=\left\langle a_{\mathrm{ijkh}}\right\rangle+\left\langle a_{\mathrm{ij} / \mathrm{m}} e_{y l m}\left(\xi^{\mathrm{kh}}\right)\right\rangle
$$

$$
\begin{gathered}
\text { Homogenized } \\
\text { values }
\end{gathered}=\begin{gathered}
\text { Average of the } \\
\text { microscopic values }
\end{gathered}+\begin{gathered}
\text { Corrective } \\
\text { term }
\end{gathered}
$$

Equation (14) proves that the macroscopic property is the sum of the average over the unit cell of the microscopic properties and a corrective term, determined from the elementary solutions $\xi^{1 \mathrm{~m}}$. The last term of the right side represents the effect of the microscopic morphology.

The elementary solution related to shrinkage does not give directly the macroscopic shrinkage, but rather the macroscopic stress field $Q_{\mathrm{ij}}$ due to shrinkage, assuming the macroscopic strain field equal to zero:

$$
Q_{\mathrm{ij}}=-\left\langle a_{\mathrm{ijkh}} s_{\mathrm{kh}}\right\rangle+\left\langle a_{\mathrm{ijkh}} e_{\mathrm{ykh}}(w)\right\rangle .
$$

The macroscopic shrinkage is then obtained through the macroscopic constitutive equation, which accounts for shrinkage. This equation comes from the combination of equations (6b) and (10):

$$
\left\langle\sigma_{\mathrm{ij}}^{(0)}\right\rangle=A_{\mathrm{ijkh}} e_{\mathrm{kh}}\left(u^{(0)}\right)-Q_{\mathrm{ij}} H .
$$

The macroscopic shrinkage $S_{\mathrm{kh}}$ is determined from equation (16), as the macroscopic strain field obtained for $H=1$, which cancels the macroscopic stress field (this is the concept of "free shrinkage"), hence:

$$
S_{\mathrm{kh}}=\left(A_{\mathrm{ijkh}}\right)^{-1} \times Q_{\mathrm{ij}} .
$$

\section{COMPUTATIONAL ASPECTS}

The homogenisation formulation results in a classical PDE (Partial Differential Equations) problem. Moreover, owing to the assumption that the microscopic and macroscopic scales are independent, together with the simple physical formulation used up to now in our laboratory (Fick's law, Fourier's law, elastic constitutive equation...), the problems under consideration are steady-state, linear and uncoupled. On the contrary, the model must be able to handle any geometry and to deal with properties that vary strongly in space. Consequently, the FE method was the chosen numerical solution strategy. In contrast with classical FE software, the model proposed here has to deal with periodic boundary conditions, which imposes constraints on the linear solver and to the mesh. In particular, each node situated at the boundary must have its "periodic" equivalent. This requirement has been fulfilled when constructing the partitioned boundaries of the unit cell contours (see Part I, [5]).

Note that the periodic boundary conditions of these problems prove that the solution does not depend on the macroscopic configuration: the elementary problems have to be solved once in order to obtain the property of the equivalent macroscopic medium.

The computational code MorphoPore, developed in Fortran 90 by one of the authors of this paper, P. Perré, has been used in this work [25, 26]. A graphical library (Winteracter 3.1) allows both pre- and post-processing with a Windows-like interface. Triangular (T3) and quadrilateral (Q4) elements can be used, with various kinds of boundary conditions (periodic, symmetrical REV, imposed macroscopic strain or stress). An efficient linear solver permits large meshes to be processed economically on typical personal computer hardware.

In this work, three node triangular elements were chosen because they provide a flexible way to follow any contour shape. The unstructured meshes are generated directly from the X-ray image. After image segmentation, the contours are extracted and smoothed. The length of each contour segment can be chosen as an input parameter (mesh refinement) for the mesh generator (see Part I, [5]).

Because the solver has to deal with periodic conditions, it is absolutely necessary to ensure that the mesh generator respect periodic positions: each node placed at the boundary face must have its corresponding node at the opposite face. Then MorphoPore generates an allocation table such that only one set of unknowns is associated to this pair of nodes. This procedure allows the number of unknowns to be significantly reduced while, at the same time, satisfying the periodic conditions. The linear systems are solved by employing the Bi-Conjugate Gradient Stabilised Method [31], together with an Incomplete Block Factorisation level zero, ILU(0), preconditioning technique.

The microscopic properties used in the calculation (see table I) come from specific experimental measurements previously made on micro-samples [3, 4].

Table I. Microscopic properties of the different components used for the calculation. These values come from specific experimental investigations $[3,4]$.

\begin{tabular}{lcccccc}
\hline & $E_{\mathrm{R}}(\mathrm{MPa})$ & $E_{\mathrm{T}}(\mathrm{MPa})$ & $v_{T R}$ & $G_{\mathrm{TR}}$ & $\alpha_{\mathrm{R}}(\% / \%)$ & $\alpha_{\mathrm{T}}(\% / \%)$ \\
\hline vessels & 1 & 1 & 0.10 & 0.45 & 0 & 0 \\
parenchyma & 1700 & 850 & 0.40 & 607 & 0.142 & 0.253 \\
fibre zone & 1900 & 1900 & 0.71 & 555 & 0.334 & 0.553 \\
ray cells & 3600 & 3800 & 0.30 & 1385 & 0.167 & 0.177 \\
\hline
\end{tabular}



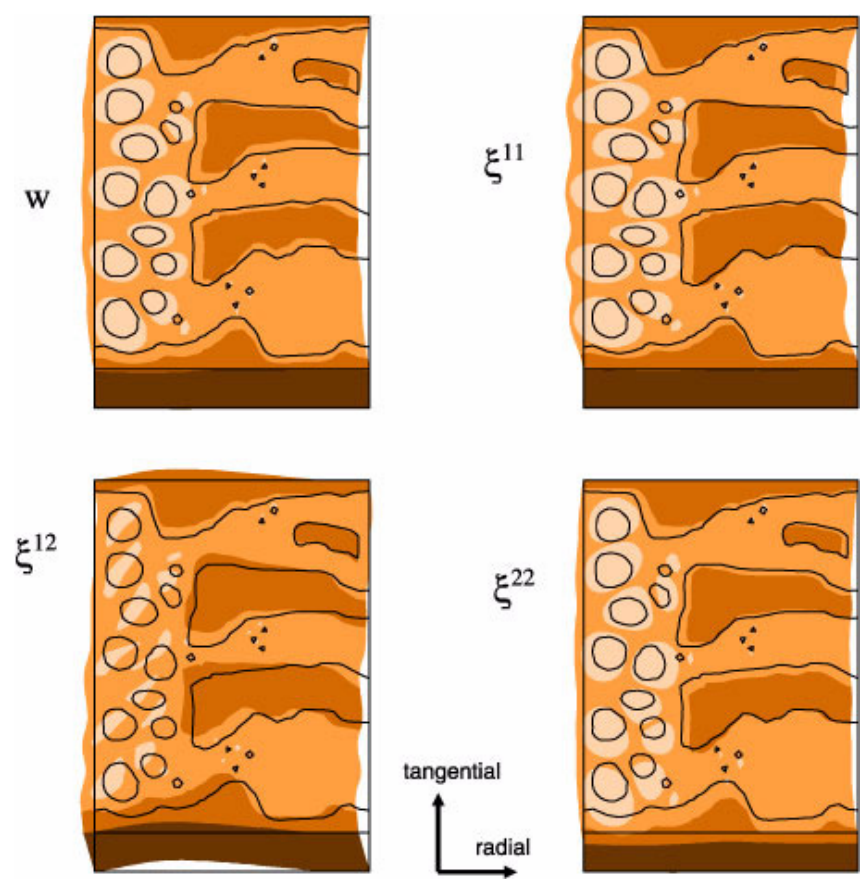

Figure 3. Periodic displacement fields computed for the four problems to be solved over the representative cell. (W) shrinkage problem; $\left(\xi_{11}\right)$ and $\left(\xi_{22}\right)$ mechanical problems in radial and tangential direction. $\left(\xi_{12}\right)$ corresponds to the shear problem. Thin lines represent the initial contours of tissues.

One typical set of solutions is drawn as the elementary displacement solutions shown in figure 3, which allows the macroscopic properties of the composite to be calculated (see table II). In figure 3, the solid lines represent the initial position of boundaries between different kinds of tissues, while the coloured zones represent the deformation of these zones as calculated for each elementary solution (an amplification factor is applied so that the deformation field can be observed easily). Vessels, ray cells and fibre zones can be recognised. These solutions emphasise the complexity of the pore structure of oak, and its implication on mechanical behaviour. In particular, it is interesting to note the following features:

- The vessels have no shrinkage and no mechanical resistance. They simply act as a degree of freedom for the structure.

- The fibre zones have an important shrinkage and are strong enough to impose this shrinkage to the rest of the structure (problem w).

- The ray cells are particularly rigid in the radial direction and have a low shrinkage in this direction.

- The ring porous zone is a weak part unable to transmit any tangential forces (in this part, the ray cell enlargement is negligible, problem 11) and prone to shear strain (problem 12).

- The weakness of the ring porous zone enables the ray cell to support any macroscopic radial forces (problem 22).

As usual with computational strategies, one has to keep in mind that satisfactory compromise has to be found between computational time, data storage requirements and accuracy. For the same X-ray raw image, several meshes have been built
Table II. Macroscopic values computed by MorphoPore for the structure depicted in figure 6 with the microscopic values of the table $I$.

\begin{tabular}{lcccc}
\hline & $E_{\mathrm{R}}(\mathrm{MPa})$ & $E_{\mathrm{T}}(\mathrm{MPa})$ & $\alpha_{R}(\% / \%)$ & $\alpha_{T}(\% / \%)$ \\
\hline average values & 1803 & 1420 & 0.188 & 0.310 \\
macroscopic values & 1465 & 1001 & 0.203 & 0.394 \\
\hline
\end{tabular}
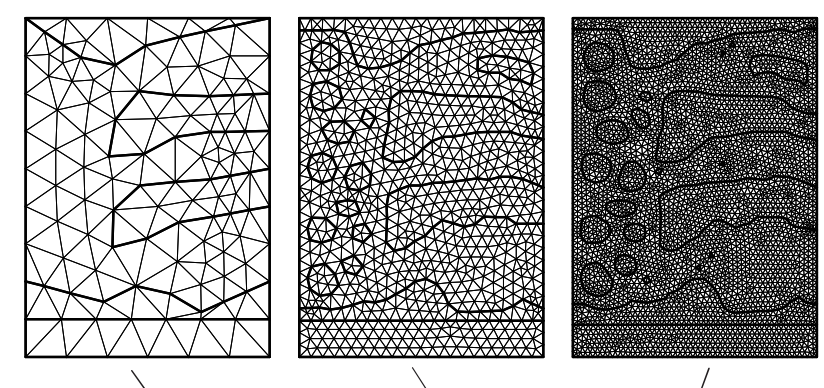

(a)



(b)



Figure 4. Effect of mesh refinement on computed macroscopic values. Relative corrections (macroscopic value divided by the averaged value) are also presented.

having various degrees of freedom (dof) ranging from a very coarse one (236 dof) up to a quite reasonably refined mesh (9848 dof). For each mesh, the number of dof comes from an exact calculation that accounts for the periodic boundary conditions and the four corners having both displacements (u and v) blocked. Figure 4 depicts the macroscopic properties calculated for these successive meshes. Note that the first mesh is so coarse that all large vessels of the initial zone have 
Table III. Macroscopic values computed by MorphoPore: effect of mesh refinement.

\begin{tabular}{lcccc}
\hline $\begin{array}{l}\text { Mesh number } \\
\text { (number of } \\
\text { degrees of } \\
\text { freedom) }\end{array}$ & $\begin{array}{c}\text { Radial } \\
\text { MOE } \\
E_{\mathrm{R}}(\mathrm{MPa})\end{array}$ & $\begin{array}{c}\text { Tangential } \\
\mathrm{MOE} \\
E_{\mathrm{T}}(\mathrm{MPa})\end{array}$ & $\begin{array}{c}\text { Radial } \\
\text { Shrinkage } \\
\text { coefficient } \\
\alpha_{R}(\% / \%)\end{array}$ & $\begin{array}{c}\text { Tangential } \\
\text { Shrinkage } \\
\text { coefficient } \\
\alpha_{T}(\% / \%)\end{array}$ \\
\hline 236 & 1971 & 1223 & 0.200 & 0.347 \\
366 & 1872 & 1174 & 0.206 & 0.359 \\
916 & 1778 & 1116 & 0.201 & 0.356 \\
1342 & 1684 & 1092 & 0.206 & 0.366 \\
1650 & 1717 & 1105 & 0.200 & 0.357 \\
2140 & 1663 & 1085 & 0.203 & 0.363 \\
2786 & 1676 & 1086 & 0.199 & 0.358 \\
4072 & 1618 & 1066 & 0.204 & 0.365 \\
4968 & 1629 & 1070 & 0.201 & 0.362 \\
6224 & 1632 & 1071 & 0.200 & 0.360 \\
7982 & 1604 & 1060 & 0.203 & 0.365 \\
9848 & 1603 & 1057 & 0.202 & 0.363 \\
\hline
\end{tabular}

disappeared. On the contrary, the large meshes are refined enough for the small vessels of the latewood zone to be accounted for. Figure $4 a$ considers directly the computed macroscopic properties. One can note that the shrinkage coefficient remains surprisingly almost independent of the mesh refinement. Both Young's moduli decrease slightly as the mesh refinement progresses. However, the variations remain small: less than 5\% between 2000 and 10000 dof (table III).

The macroscopic property changes result from two different reasons:

- the accuracy of the FE calculations increases with the mesh refinement;

- the shapes and proportions of each phase change with the segment length used to describe the tissue morphology.

In order to improve the analysis, figure $4 b$ exhibits the dimensionless macroscopic properties, which have been calculated as the ratio of the macroscopic property divided by the average of the microscopic properties (see Eq. (14)). Keeping in mind that the averaged shrinkage has to be weighted by the material stiffness, the dimensionless macroscopic shrinkage is calculated according to the following expressions:

Radial shrinkage $\quad S_{11}^{*}=\frac{S_{11}}{\left(A_{11 \mathrm{ij}}\right)^{-1}\left\langle a_{\mathrm{ijkl}} s_{\mathrm{kl}}\right\rangle}$.

Tangential shrinkage $S_{22}^{*}=\frac{S_{22}}{\left(A_{22 \mathrm{ij}}\right)^{-1}\left\langle a_{\mathrm{ijkl}} S_{\mathrm{kl}}\right\rangle}$

Figure $4 b$ highlights that the dimensionless macroscopic shrinkage varies as the mesh refinement changes. However, for the annual ring pattern under consideration, this second graph confirms that above 2000 dof, the variations of macroscopic behaviour are almost negligible. In the forthcoming results, all meshes are built with a segment length that produces a resolution comparable to the mesh with 5000 dof.

\section{SOME COMPUTATIONAL EXAMPLES}

The complete analysis, from the wood cross-section to homogenised properties, provides completely new possibilities in the study of relationships between tree development and wood properties. The following examples illustrate the main callings of this tool. The first application depicts the effect of fibre proportion and fibre shape on the elastic and shrinkage values. It uses a real X-ray image of an oak sample that has been modified in order to vary the fibre proportion (annual ring width) and/or the fibre pattern (triangles, rectangles and no fibre zones). The shapes are such that the fibre proportion does not change between triangles and rectangles. As expected, computed results exhibit an increase of shrinkage and moduli when the ring width, hence the density, increases (figure 5). This result is in accordance with usual experimental data and well-known statistical trends [9]. The new contribution of this work is that this effect is quantified. In addition, for the first time, it becomes possible to differentiate the effect of tissue morphology from the effect of tissue proportion. For all of the calculated properties, the effect of the fibre is slightly higher for triangular shaped zones. Such possibilities offer an interesting potential for genetic selection.

In order to focus the attention on the effect of growth conditions, a second example is proposed that deals with actual anatomical patterns. Two positions of the same tree have been selected. The second position, which is taken just after thinning the forest stand, exhibits a very large annual ring $(3.1 \mathrm{~mm}$ instead of $1.7 \mathrm{~mm}$ ). Homogenisation calculations have been performed on each of these zones. According to the remark specified in the "representation" section, these calculations allow us to quantify the wood material that would have been produced by this tree with a regular growth rate (thin annual ring for the first REV and large annual ring for the second).

A first observation shows that the computed values are very reasonable compared with the usual data proposed in literature. For example, the renowned anisotropy of oak is clearly present for the mechanical properties with a factor lower than 2 [15]. Furthermore, the anisotropy also is pronounced for the shrinkage properties, with a factor close to two [24].

A more detailed analysis reveals that, due to the large extension of the fibre zones with the annual ring width, all homogenised parameters exhibit higher values for the large annual ring (figure 6). In particular:

- the shrinkage coefficients increase by $17 \%$ and $18 \%$;

- the Young's modulus increases by a significant factor in the tangential direction $(+23 \%)$;

- the Young's modulus is slightly modified in the radial direction $(+11 \%)$.

These effects result from the spatial distribution of tissues in oak. Due to the presence of the initial porous zone (large vessels elaborated in earlywood), only the ray cells are able to constitute a continuous mechanical pathway in the radial direction from one ring to the other. The rigidity of the fibre 



Figure 5. Effect of growth width and fiber zones pattern on elastic and shrinkage properties of Oak in the radial-tangential plane (virtual annual rings).

zones is altered in the radial direction by the presence of vessels, while the same zones are able to act efficiently in the tangential direction.

The increase of shrinkage in the tangential direction has to be connected with the increase in the fibre zones, but also with the increase in fibre proportion within latewood when the annual ring width is large. This result is in agreement with the experimental data described by Botosso [7] who observed a

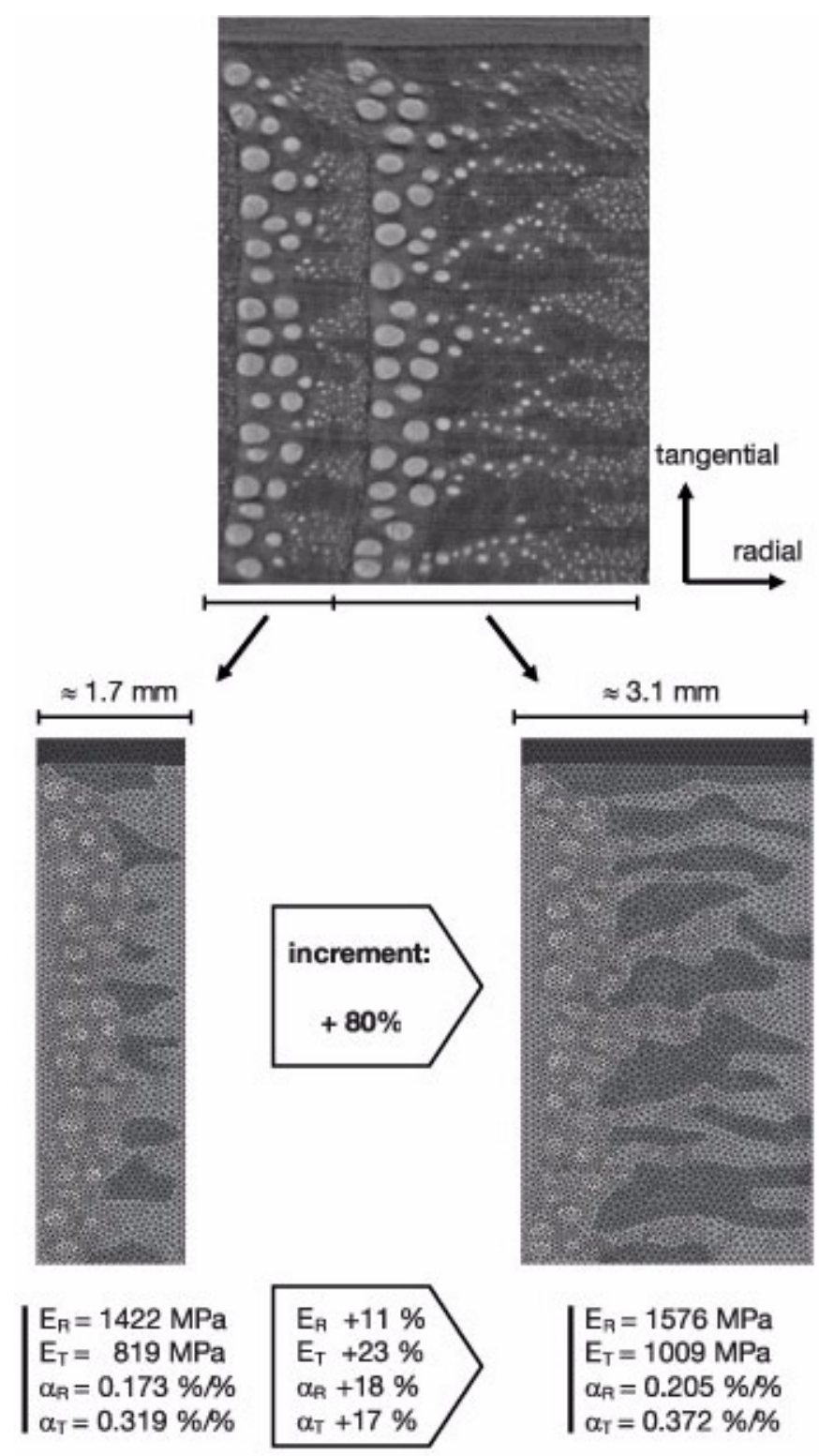

Figure 6. Effect of growth width and fiber pattern on elastic and shrinkage properties of Oak in the radial-tangential plane (Actual annual rings). The microscopic properties of each tissue are supposed to be identical in the two configurations.

great correlation between the presence of a fibre zone in latewood and tangential shrinkage. The value of the radial shrinkage coefficient results from a balance between the large shrinkage value of the fibre zones and the small shrinkage value of the ray cells.

\section{LOCALISATION}

The formulation offers the possibility, through a procedure called localisation, to calculate the microscopic stress field 


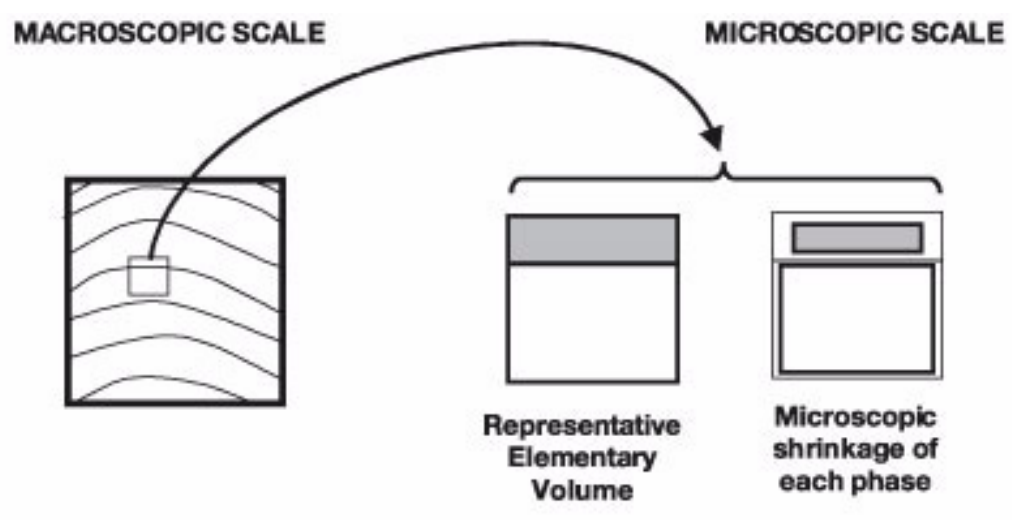

"FREE" SHRINKAGE

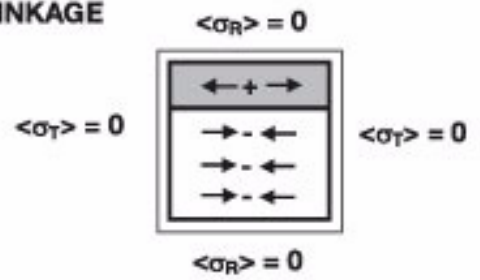

Figure 7. Localisation principle: while homogenisation allows the macroscopic properties to be calculated from microscopic data, localisation allows the microscopic stress field resulting from macroscopic configurations to be determined. Three macroscopic configurations have been chosen in this work. that results from any macroscopic loading. In the case of wood, localisation is of utmost importance. For example, it allows the checks due to shrinkage in the latewood part of softwood to be understood, and even predicted. Indeed, due to the heterogeneity, some parts of the REV that have high (low) shrinkage values will undergo microscopic tensile (compressive) stresses (figure 7). This is easy to understand in the case of series or parallel structures.

In general, a rigorous formulation can be derived to calculate these microscopic stress fields. Once the four solutions have been calculated for the four problems to be solved over the unit cell, the microscopic stress and strain fields that result from a macroscopic loading can be calculated from the following expression:

$$
\begin{aligned}
\sigma_{\mathrm{ij}}^{(0)}= & e_{\mathrm{xkh}}\left(u^{(0)}\right)\left\{a_{\mathrm{ijk} /}+a_{\mathrm{ij} / \mathrm{m}} e_{\mathrm{y} / \mathrm{m}}\left(\xi^{\mathrm{kh}}\right)\right\} \\
& +H\left\{a_{\mathrm{ijk}}\left(e_{\mathrm{y} / \mathrm{m}}(w)-s_{\mathrm{kh}}\right)\right\} .
\end{aligned}
$$



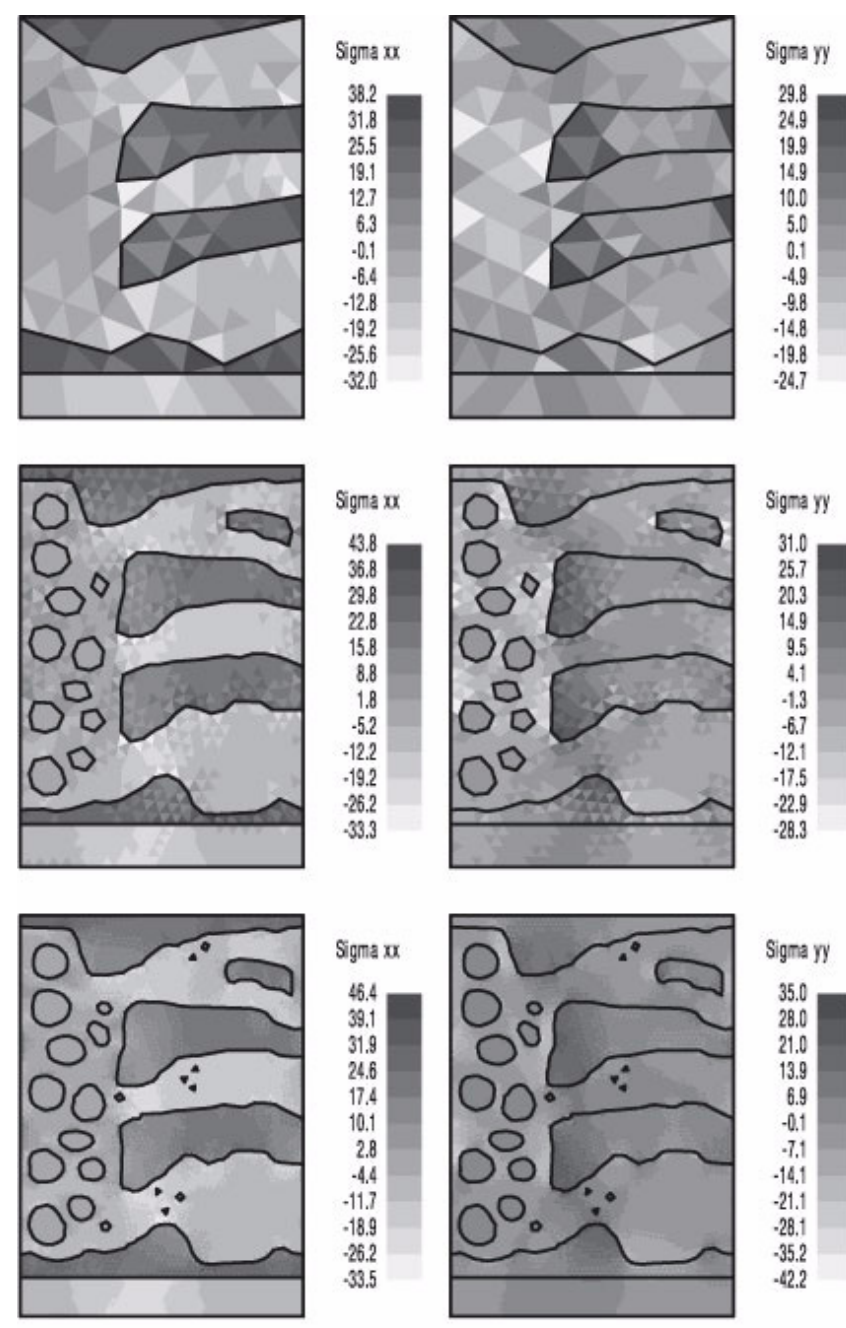

Figure 8. Localization solutions: effect of mesh refinement on the computed stress field.

In equation (20), the macroscopic values, $e_{\mathrm{xkh}}\left(u^{(0)}\right)$ and $H$ arise from a classical elastic solution computed at the macroscopic scale using the equilibrium equation and the macroscopic constitutive equation (Eq. (16)).

The first selected example deals with a very important problem in wood science - the problem of free shrinkage. In this example, the macroscopic conditions are just the absence of the macroscopic stress field $\left\langle\sigma_{\mathrm{ij}}^{(0)}\right\rangle$ and the presence of shrinkage $\left(H=-X_{\mathrm{fsp}}\right)$, for an oven-dried sample, see Eq. (2). From equation (16), the macroscopic strain field $e_{\mathrm{xkh}}\left(u^{(0)}\right)$ to be used in equation (20) is obvious.

This is exactly what is usually called "free shrinkage". Obviously, because the structure is heterogeneous, microscopic stress is generated by shrinkage, even if no macroscopic load exists (figure 7). Indeed, stresses are generated because the microscopic strain field due to local shrinkage does not fulfil the geometrical compatibility.
In the previous section, some considerations on the mesh refinement led to the conclusion that the calculated macroscopic values are quite accurate as soon as the mesh is reasonably detailed. However, the calculation of the microscopic stress field does take advantage of the same averaging effect. So, it is natural to be cautious of important deviations from the solution even for refined meshes. This is why the same meshes have been used to analyse the effect of mesh refinement on the local microscopic stress field (figure 8). Surprisingly, the calculated microscopic stress level has a satisfactory value even for very coarse meshes. In this figure, the legend of each figure depicts the stress value between the extreme values. There is no doubt from these results that the microscopic stress value is accurate enough for the same level of resolution that was used for the calculation of the macroscopic values.

Figure 9 depicts the REV morphology and microscopic stress fields calculated in such conditions. Some important effects should be noted:

- a quite important shear stress field exists. This results from the two-dimensional property variations over the REV (this field does not exist with multi-layered materials such as softwoods);

- the fibre zones are rigid enough to allow a large shrinkage to develop within the structure. Consequently, fibre zones undergo important tensile stresses in the tangential direction $\sigma_{\mathrm{TT}}$;

- the radial shrinkage coefficient is about the same for the fibre and parenchyma zones. On the opposite, radial shrinkage is low for ray cells. This is why free macroscopic shrinkage induces radial compressive stress within ray cells and radial tensile stress in fibre and parenchyma zones.

The second example of localisation has been chosen from one important industrial operation. Wood drying is always difficult to control, and is specifically difficult for oak. The following example represents what happens close to the exchange surface when the moisture content just decreased below the fibre saturation point. This phenomenon occurs just when the drying stresses develop, so that the elastic formulation used in this work is not unrealistic. Shrinkage occurs near the surface while the core of the board remains within the domain of free water. Consequently, shrinkage occurs with almost no macroscopic deformation along the direction parallel to the exchange surface. The macroscopic coefficients to be used in equation (20) depend on the sawing pattern (figure 7):

- $\left\langle\sigma_{\mathrm{tt}}^{(0)}\right\rangle=0 ; \mathrm{e}_{\mathrm{xrr}}\left(u^{(0)}\right)=0$ and

$\left\langle\sigma_{\mathrm{rt}}^{(0)}\right\rangle=0 ; \mathrm{e}_{\mathrm{xrt}}\left(u^{(0)}\right)=0$ for a quartersawn board;

- $\left\langle\sigma_{\mathrm{rr}}^{(0)}\right\rangle=0 ; \mathrm{e}_{\mathrm{xtt}}\left(u^{(0)}\right)=0$ and

$\left\langle\sigma_{\mathrm{rt}}^{(0)}\right\rangle=0 ; \mathrm{e}_{\mathrm{xrt}}\left(u^{(0)}\right)=0$ for a flatsawn board.

In each case, the missing part of $\mathrm{e}_{\mathrm{xkh}}\left(\mathrm{u}^{(0)}\right)$ is determined to fulfil equation (16), the value of $\mathrm{H}$ used in the calculation is $10 \%$ (one third of the hygroscopic range). Figures $10 a$ and $10 \mathrm{~b}$ depict the local stress field determined from these macroscopic loading configurations respectively. As expected, due 



Figure 9. Localization: micro-stress fields computed in the case of free macroscopic stress (often called "free shrinkage" in wood science) . Red color $=$ positive values; Blue color $=$ negative values. to shrinkage, all stress values along the constrained direction are positive (tension stress): $\sigma_{\mathrm{rr}}$ in figure $10 \mathrm{a}$ and $\sigma_{\mathrm{tt}}$ in figure $10 \mathrm{~b}$. In the corresponding fields, the presence of vessels becomes obvious, with very low values of $\sigma_{\mathrm{tt}}$ in figure $10 \mathrm{~b}$ (no tangential rigidity in the ring porous zone) and low values of $\sigma_{\mathrm{rr}}$ in figure $10 \mathrm{a}$ for the latewood part situated in series within the vessel zone. In this figure, the stress level is much higher close to and within the ray cells. In the case of a flatsawn board (figure 10b), the tangential stress level is rather high in the ray cells, especially in regions in series within fibre zones. This observation has to be related to a well-known behaviour of oak, which is prone to checking within ray cell during drying.

In the direction that is normal to the exchange surface, no geometrical constraint exists and the average value of the stress field is equal to zero. The stress levels are low in this direction $\left(\sigma_{\mathrm{t}}\right.$ in figure $\left.10 \mathrm{a}\right)$, except the phenomenon already exhibited in the free shrinkage problem, namely the contrast of the shrinkage values in the radial direction between fibre zones and rays cell (see the large compression stress in ray cells observed for $\sigma_{\mathrm{rr}}$ in figure $10 b$ ).

\section{CONCLUSION AND PROSPECTS}

In this two part paper, a complete suite of tools has been developed to enable the determination of the elastic and shrinkage properties of oak from its anatomical pattern. Homogenised properties are computed on finite element a)

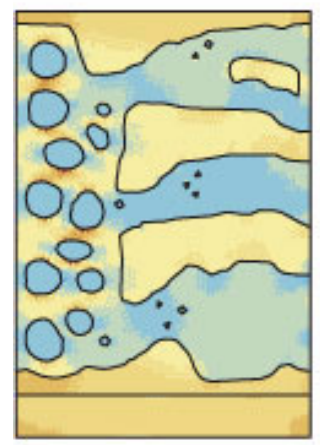

b)

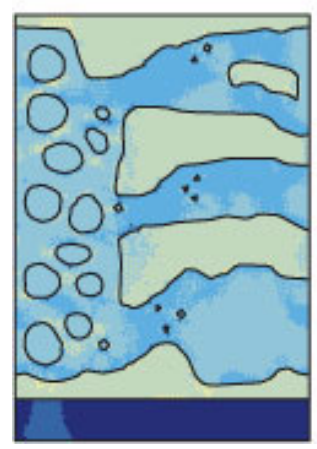

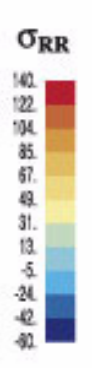

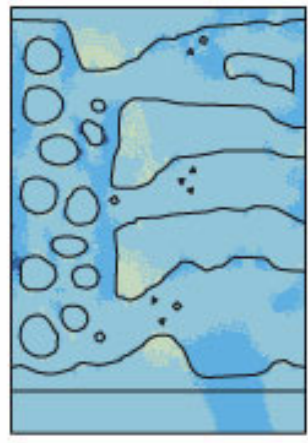

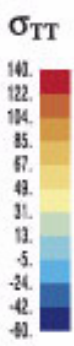
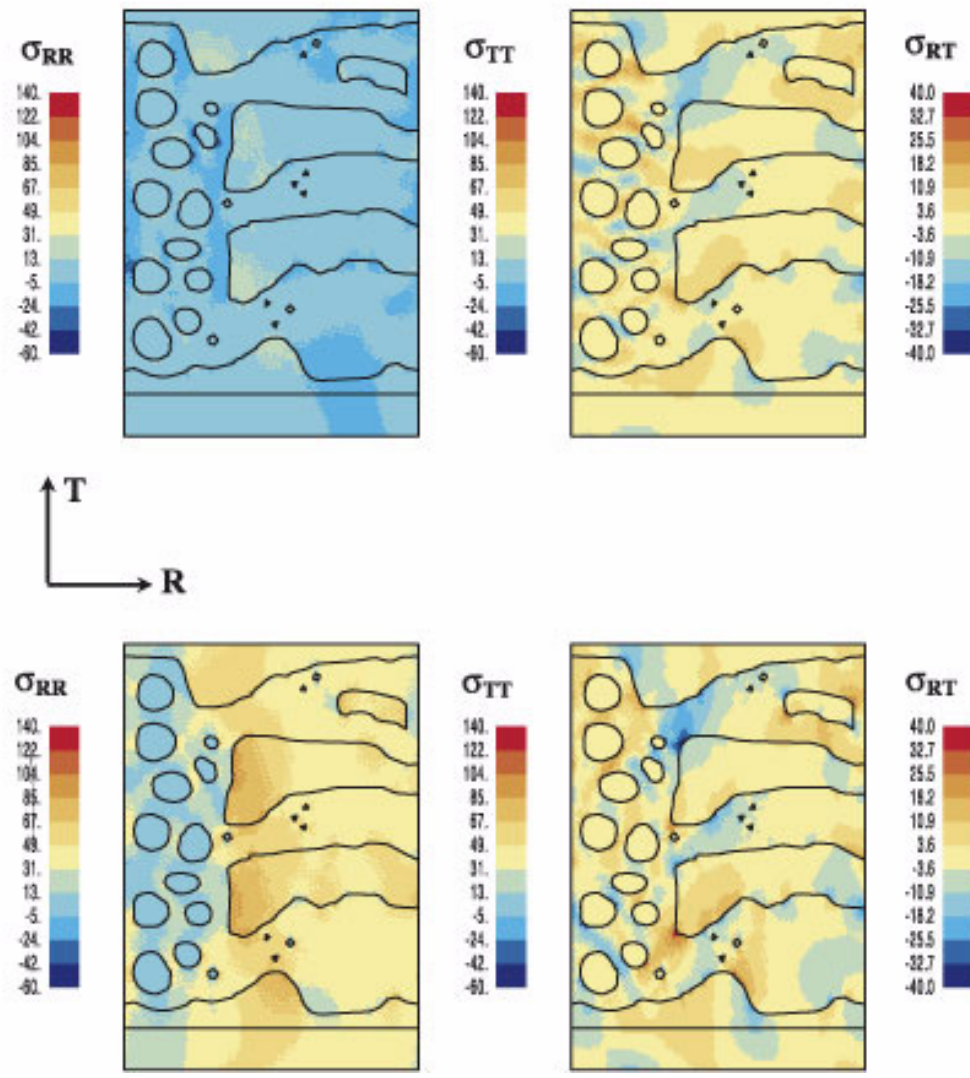
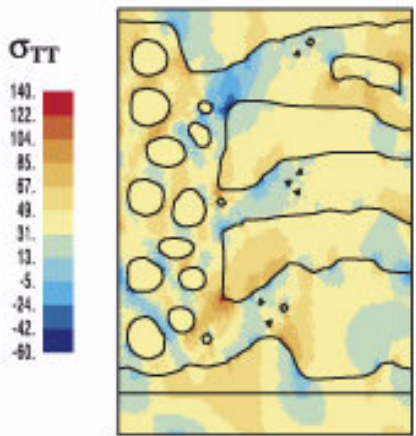

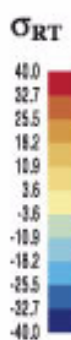

Figure 10. Localization: microstress fields computed in the case of constrained macroscopic deformation (case of drying conditions). Red color $=$ positive values; blue color $=$ negative values). (a): $\left\langle\varepsilon_{\mathrm{RR}}>=0 .(\mathrm{b}):<\varepsilon_{\mathrm{TT}}>=0\right.$. 
meshes generated directly from X-ray images of real oak samples. Shrinkage coefficients and elastic properties can be computed in the transverse plane (radial-tangential).

Several examples were proposed, which prove that the effect of tissue proportion can be separated from the effect of tissue morphology. A test performed on two different parts of one single tree allowed the effect of growth ring width on wood properties to be quantified.

Two different localisation solutions were also proposed: free shrinkage of wood and drying of wood. Each component of the stress tensor field can be visualised within the unit cell. By this way, the risk of structure damage can be evaluated not only according to the macroscopic loading, but also according to the anatomical pattern.

Such an approach has a great potential for studying wood quality in relation to growth conditions of trees. It could also provide objective criteria for genetic selection.

Obviously, the method proposed here should be used only as a tool. One must keep in mind that several problems remain to be solved, including the treatment of other spatial scales and the difficult problem of property characterisation at the microscopic scale.

In addition, one must keep in mind that the model has to be validated. This work is in progress in our laboratory. The results of computations should be compared to experimental values that should be measured on the same samples.

\section{REFERENCES}

[1] Adler P.M., Porous Media: Geometry and Transports Butterworth-Heinemann Series in Chemical Engineering, 1992.

[2] Astley R.J., Harrington J.J., Stol K.A., Mechanical Modelling of Wood Microstructure, an Engineering approach, Proceedings IPENZ conference, 1996.

[3] Badel É., Perré P., Détermination des propriétés élastiques d'éléments individuels du plan ligneux du chêne par des essais de traction sur micro-éprouvettes, Ann. For. Sci. 56 (1999) 467-478.

[4] Badel É., Perré P., Using a digital X-ray imaging device to measure the swelling coefficients of a group of wood cells, NDT\&E International 34 (2001) 345-353.

[5] Badel É., Perré P., Predicting Oak Wood Properties using X-ray Inspection: Representation, Homogenisation and Localisation. Part I: Digital X-ray imaging and representation by Finite Elements, Ann. For. Sci. 59 (2002) 767-776.

[6] Barkas W.A., The influence of ray cells on the shrinkage of wood, Transactions of the Faraday Society 37 (1941) 535-548.

[7] Botosso P.C., Une méthode de mesure du retrait microscopique du bois, Ph.D. Thesis, Université de Nancy I, 1997.

[8] Boutelje J.B.,The relationship of structure to transverse anisotropy in wood with reference to shrinkage and elasticity, Holzforschung 16 (1962) 33-46.

[9] Eyono Owoundi R., Modélisation de la rétractibilité du bois en relation avec des paramètres de la structure de l'accroissement annuel et de la position dans l'arbre chez Quercus Robur L. et Q. Petraea Liebl, Ph.D. Thesis, ENGREF, Nancy, 1992.

[10] Farruggia F., Détermination du comportement élastique d'un ensemble de fibres de bois à partir de son organisation cellulaire et d'essais mécaniques sous microscope, Ph.D. Thesis, ENGREF, Nancy, 1998.
[11] Farruggia F., Perré P., Microscopic tensile tests in the transverse plane of earlywood and latewood parts of spruce, Wood Sci. Tech. 34 (2000) 65-82.

[12] Gibson L.J., Ashby M.F., Cellular solids, structure and properties, Pergamon Press, 1988.

[13] Gillis P.P., Orthotropic elastic constant of wood, Wood Sci. Tech. 6 (1972) 138-156.

[14] Guitard D., El Amri F., La fraction volumique en rayons ligneux comme paramètre explicatif de la variabilité de l'anisotropie élastique du matériau bois, ARBOLOR, Actes du $2^{\mathrm{e}}$ colloque Sciences et Industrie du Bois (1987) 405-412.

[15] Guitard D., Fournier M., Mécanique du matériau bois et composites, in: Arbolor (Ed.), Le bois matériau d'ingénierie, 1994. pp. $91-125$.

[16] Holmberg S., Persson K., Petersson H., Nonlinear mechanical behaviour and analysis of wood and fibre material, Comput. Struct. 72 (1999) 459-480.

[17] Hornug U., Homogenization and porous media, Springer-Verlag, New York, 1997.

[18] Keller R., Thiercelin F., Influence des gros rayons ligneux sur quelques propriétés du bois de hêtre, Ann. Sci. Forest. 32 (1975) $113-129$.

[19] Kelsey K., A critical review of the relationship between the shrinkage and structure of wood, Division of Forest products technological paper No. 28, CSIRO, Melbourne, 1963.

[20] Koponen S., Toratti T., Kanerva P., Modelling elastic and shrinkage properties of wood based on cell structure, Wood Sci. Tech. 25 (1991) 25-32.

[21] L'Hostis G., Contribution à la conception et à l'étude de structures composites thermoélastique, Ph.D. thesis, Université Paris VI, 1996.

[22] Mariaux A., Narboni Ph., Anisotropie du retrait et structure du bois : essai d'approche statistique, Bois For. Trop. 178 (1978) 36-44.

[23] Masserann C., Mariaux A., Anisotropie de retrait et structure du bois. Recherche de l'influence des caractères morphologiques transverse des fibres, Bois For. Trop. 209 (1985) 35-47.

[24] Nepveu G., Variabilité, in: Arbolor (Ed.), Le bois matériau d'ingénierie, 1994, pp. 128-182.

[25] Perré P., Image Analysis, Homogenization, Numerical Simulation and Experiment as Complementary Tools to Enlighten the Relationship between Wood Anatomy and Drying Behavior, Drying Tech. J. 15 (1997) 2211-2238.

[26] Perré P., The Use of Homogeneisation to Simulate Heat and Mass Transfer in Wood: Towards a Double Porosity Approach' Plenary lecture, International Drying Symposium, published in Drying'98 (1998) 57-72, Thessaloniki, Greece.

[27] Perré P., Wood as a multi-scale porous medium: Observation, Experiment, and Modelling, keynote lecture, 1st International conference of the European Society for wood mechanics, Lausanne, Switzerland (2001) 403-422.

[28] Sanchez-Hubert J., Sanchez-Palencia E., Introduction aux méthodes asymptotiques et à l'homogénéisation, Masson, Paris, 1992.

[29] Sanchez-Palencia E., Non-homogeneous media and vibration theory, Lecture Notes in Physics, 127, Springer Verlag, 1980.

[30] Suquet P.M., Element of homogenization for ineslastic solid mechanics in Homogenization Techniques for Composite media, Lecture Notes in Physics, 272, Sanchez-Palencia and Zaoui (Ed.), Springer-Verlag, 1985.

[31] van der Vorst H.A., Bi-CGSTAB: a fast and smoothly converging variant of Bi-CG for the solution of nonsymmetric linear systems, SIAM J. Sci. Stat. Computat. 13 (1992) 631-645.

[32] Watanabe U., Norimoto M., Ohgama T., Fujita M., Tangential Young's modulus of coniferous early wood investigated using cell models, Holzforschung 53 (1999) 209-214. 